\title{
CORES, NOMES, POEMAS E AFETOS PENSANDO A ESCRITA VISUAL EM CAPAS DE DISCO A PARTIR DE CAPAS DE CAETANO VELOSO
}

Ä̈cha A. de Figueirêdo Barat é mestre em História da Arte pela Paris I - Panthéon Sorbonne e doutoranda em Literatura, Cultura e Contemporaneidade na PUC-Rio (bolsista FAPERJ nota 10). E-mail: aichafigueiredo@gmail.com

\section{Resumo}

Este é um trabalho que entende as capas de disco como uma forma de escrita. Partindo da leitura da capa de Cores, nomes, de Caetano Veloso e remetendo às de outros discos seus, o artigo discorre sobre o quanto a inventividade neste suporte articula-se ao conteúdo sonoro das canções, mas também a aspectos da própria carreira de Caetano Veloso e de sua persona enquanto figura pública.

\begin{abstract}
This paper considers the album cover as a form of text. By proposing a reading of the album cover of Cores, nomes, by Caetano Veloso, and other albums of his, this article discusses how this support presents important echoes of the album's content, its songs, but also of Caetano Veloso's own career as well as his persona as a public figure.
\end{abstract}

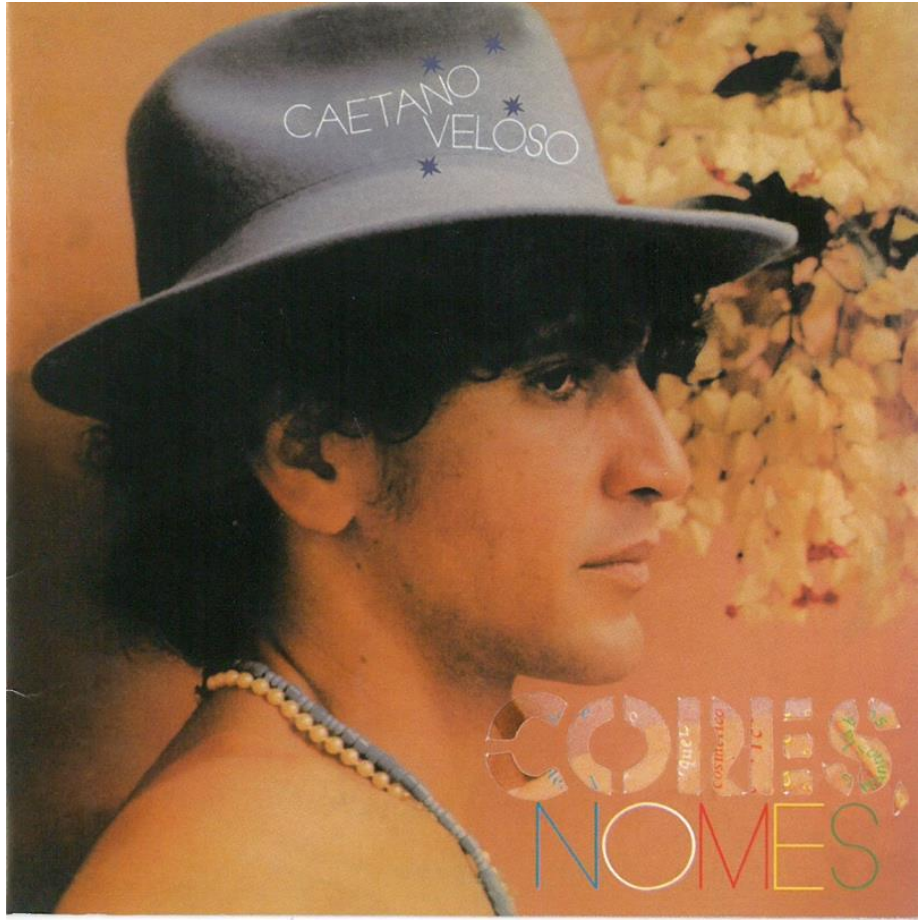

Imagem 1: capa do disco Cores, nomes.

É curioso pensar que pouco se escreveu sobre Cores, nomes [Imagem 1], de Caetano Veloso. Ao consultar uma extensa bibliografia sobre a obra do artista, quase nada se lê sobre esse disco do auge comercial de sua carreira. Lançado em 1982, ele teve sua capa concebida por Oscar Ramos e Luciano Figueiredo - uma das mais complexas visualmente da discografia de Caetano. Mas Cores, nomes se apresenta como um disco de várias camadas. Por isso, a qualquer leitura que pretenda revelar os múltiplos aspectos que contribuem para sua riqueza visual cumpre estar afinada com a qualidade híbrida deste objeto disco e atentar para os diferentes componentes que nele estão em jogo.

É importante perceber que toda capa é, antes de receber qualquer cor ou nome, uma embalagem. Logo, antes de empreendermos a leitura de elementos plásticos de Cores, nomes, caberá fazermos um preâmbulo que o situe naquele contexto em que o 
suporte disco atingiu seu auge. A chegada do LP mudou a indústria fonográfica. Pela primeira vez, era possível fugir das restrições técnicas que impunham aos $78 \mathrm{rpm}$ uma limitação temporal - apenas uma faixa por lado. Já o LP, assim como sua capa, se tornava uma tela em potencial: permitiu que o disco gravado se tornasse arte - das capas incríveis às ideias que encadeavam uma música na outra. Nos anos 1960 e 1970, as vendas estratosféricas de disco fizeram a indústria fonográfica mundo afora explodir. No Brasil, onde a música age como uma das mais fortes e abrangentes expressões da cultura $^{1}$ popular $^{2}$, o disco foi, durante muito tempo, o ponto inicial e crucial no processo de comunicação do artista com o grande público. Tornou-se produto consumido pelos mais diversos segmentos da população e o maior veículo de trabalho dos artistas até meados dos anos 1990.

Todavia, nem sempre o cuidado estético com as capas foi uma questão para as gravadoras. Foi somente no encalço de uma série de modernizações que o país atravessou nos anos 1950 que ocorreram transformações fundamentais para a comunicação das capas de disco ${ }^{3}$. As gravadoras e a indústria fonográfica em geral passaram a ter uma preocupação maior com o apelo visual de suas capas, sempre visando ao sucesso mercadológico. Não por acaso, veio desse sucesso um anseio de conceber capas visualmente fortes. Cores, nomes testemunha, reforça e demonstra como as capas podem fazer parte de um projeto mais amplo do artista e que, portanto, há uma demanda de mapeamento, leitura e compreensão desse fenômeno.

O álbum é espaço híbrido por definição, já que coloca em tensão e diálogo a sequência temporal da música e a simultaneidade plástica de sua parte visual. Ao mesmo tempo em que está inscrito na duração de sua audição, o disco tem sua capa, que o materializa no espaço. É fundamental, contudo, lembrar que, ainda que se trate de um objeto artístico, jamais podemos perder de vista a função comercial desse objeto de estudo, posto que era - salvo raríssimas exceções - produto da indústria fonográfica, do que anteriormente chamávamos cultura de massas ${ }^{4}$ e hoje chamamos cultura midiática ${ }^{5}$. Assim, colocar em evidência a singularidade da capa de Cores, nomes e pensá-la como forma de escrita de forma alguma nos obriga a ignorar que sua natureza de produto também participa dessa escrita.

\footnotetext{
${ }^{1}$ O próprio Caetano Veloso afirma, em entrevista do livro Patrulhas ideológicas: "O caso do Brasil, com música popular, é especial; é muito forte o mercado de música popular, é muito grande o interesse pelo que se faz... inclusive o status intelectual e político da criação de música popular no Brasil. É aberrante esta importância: todo mundo intui uma força cultural, política, intelectual e filosófica na música popular brasileira. E isso existe porque a música popular é muito forte, vem muito de dentro, expressa e atua muito sobre o país. [...] Não poderia haver tudo isso se não houvesse de fato uma 'força estranha' na música popular no Brasil...” (DE HOLLANDA; PEREIRA, 1980, p. 106).

${ }^{2}$ No Brasil, a separação entre cultura popular e cultura de massa nem sempre é clara na música - posto que a cultura de massa tem forte substrato na cultura popular.

${ }^{3}$ Considera-se que as grandes transformações e inovações visuais em capas se deram a partir da Bossa Nova.

${ }^{4}$ A cultura de massa conforme descrita por teóricos como Horkheimer e Adorno é levada à padronização pelo monopólio da indústria cultural.

${ }^{5}$ A cultura midática está atrelada aos meios, ou seja, às mídias: rádio, televisão, disco, e hoje internet (vídeos em streaming, MP3 e música em streaming). A música sempre esteve atrelada não só ao suporte disco como em consonância com programas de rádio, televisão ( $O$ fino da bossa; Divino Maravilhoso; Festivais da canção etc.).
} 
Para situar o trabalho em um recorte histórico ${ }^{6}$, e tendo em vista que estamos tentando entender as capas como manifestações discursivas, parto de uma consideração teórica proposta por Karl Erik Schollhammer:

[...] não há mais dúvida sobre a superioridade contemporânea da representação visual em termos de eficiência de divulgação e de impacto sensível sobre o público. O sucesso dos meios de comunicação deve-se em parte à facilidade de percepção e ao automatismo com que o público absorve a imagem viva (SCHOLLHAMMER, 2007, p. 9).

Enquanto peça do mercado fonográfico, uma boa capa, ou uma capa que queira ser vista como um projeto maior, deve levar em conta alguns atributos: ser sedutora, original e informativa. Mas ser também uma capa diferente de outras e com a qual o público possa se identificar. Contudo, fora isso - e segundo a observação de Schollhammer -, parece essencial entender a capa para além da simples ilustração e compreendê-la não somente como invólucro ou peça de design, mas também como objeto que se faz e se assume como artístico, que se quer (e que pode se tornar) tão importante quanto o conteúdo sonoro. Tudo isso a partir, é claro, de seu impacto sensível. Cabe esclarecer que, ainda que possam ser consideradas formas de arte, o design, assim como a arquitetura, abarca uma função utilitária que lhes é intrínseca. Uma capa de disco, ainda que artística, nunca perde de vista sua função - embalar o disco.

Levando isso em consideração, trataremos Cores, nomes como uma capa que explora as múltiplas possibilidades de um meio de expressão que trabalha com as dimensões de tempo e espaço. Tempo das sequências das músicas, a duração dos lados (A e B), um tempo de audição que permite que se compreenda um encadeamento, em que pausas adquirem mais significado e o silêncio, entre músicas, é o riscar de uma agulha. Espaço onde diferentes sistemas de códigos visuais entram em jogo. Em suma, a especificidade do suporte disco propicia uma relação também singular entre design, arte e som. Capa, encarte, textos de acompanhamento (que podiam ser escritos pelos próprios artistas ou por terceiros), estratégias de lançamento, figurinos - tudo se agenciava para fazer do álbum um acontecimento importante. Com todos esses componentes, o álbum tornou-se uma mídia que - como muitos artistas perceberam permitiu (e convidou a) conjugar som e imagem de formas criativas.

Assim, é importante pensar o disco como um todo. Como aponta Schollhammer:

[...] já não podemos mais tratar a imagem como ilustração da palavra nem o texto como explicação da imagem. É o conjunto texto-imagem que, ao formar um complexo heterogêneo, se torna o objeto fundamental para a compreensão das condições representativas em geral (SCHOLLHAMMER, 2007, p. 17).

As capas de disco no Brasil foram locus privilegiado de expressão para inúmeros fotógrafos e artistas plásticos consagrados. Efetivamente, quando nos deparamos com

\footnotetext{
${ }^{6}$ A partir do final dos anos 1950, quando a capa começa a ser verdadeiramente pensada. Revista Escrita 
capas de grandes nomes da música brasileira, se atentarmos para os encartes, notaremos que, em muitos casos, essas capas foram feitas por algum artista renomado. Esse foi, sem dúvida, um campo de atuação muito fértil para artistas plásticos aplicarem seu trabalho em escala industrial.

A consciência dessa fertilidade se nota até mesmo no discurso de capistas e músicos. O artista plástico Tunga (2015, informação verbal) disse que capas de disco são como cascas de fruta: "Você tira a casca e degusta o fruto: algumas cascas são excepcionais". Jards Macalé (2014, informação verbal), por sua vez, exaltou a capa de disco como "um objeto de desejo, de prazer estético maravilhoso". Essas falas encontram eco e ilustração em Cores, nomes, em que é o colorido e a identidade mais externa e material que chamam atenção e convidam, à primeira vista. Há muitos casos, então, em que o capista deixa de ser um mero ilustrador para se tornar um colaborador do álbum.

Numa análise preliminar da capa de Cores, nomes, percebemos o cantor usando um chapéu azul, um colar e uma guia. A imagem parece até muito simples: o cantor de perfil com o muro ao fundo, numa apresentação quase ton sur ton (que lembra a capa de seu disco anterior: Outras palavras [Imagem 2]. Mas quando olhamos mais atentamente - ou quando manuseamos o encarte e a capa - vemos que se trata de um caso especial.

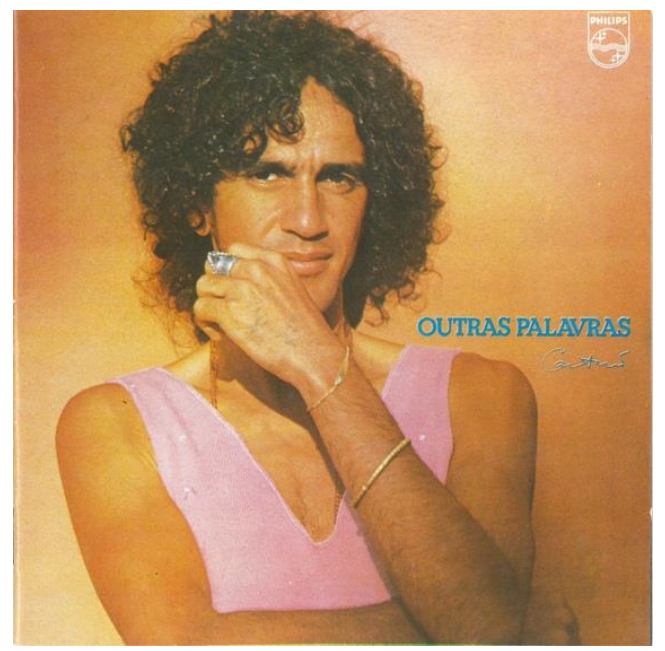

Imagem 2: capa do disco Outras palavras.

Em um primeiro momento, vê-se mais uma capa onde há a fotografia do artista estampada, tendência que sempre dominou a identidade visual de capas em todo o mundo. A fotografia é um vetor crucial, pois trouxe inegavelmente uma identidade visual a muitos músicos e bandas e os transformou em mitos. Como aponta Susan Sontag (2015, p. 84), “[a] fotografia tornou-se a arte fundamental das sociedades prósperas, perdulárias, inquietas - uma ferramenta indispensável da nova cultura de massa que tomou forma". A presença do retrato do artista na capa permite uma associação imediata do público com o som contido no disco. É pertinente pensar esse 
tipo de capa em paralelo com a tradição do gênero pictórico do retrato (do italiano ritratto e do francês portrait - par trait: por $\operatorname{traço}^{7}$ ). Como aponta Shearer West:

Talvez mais do que qualquer outra forma de arte, o retrato se manifeste em formas variadas de mídia. Retratos podem ser pinturas, esculturas, desenho, gravuras, fotografias, [... podem aparecer em jornais ou revistas ou em mosaicos, cerâmicas, tapeçarias ou cédulas de dinheiro. (WEST, 2004, p.13) ${ }^{8}$

Consequentemente, considerar a capa como uma forma de retrato parece ser um percurso teórico necessário. A fotografia é um vetor crucial para representar o artista e contribui para sua mitificação. O retrato é a imagem da pessoa ausente, uma pose, uma encenação e uma desconstrução do biográfico. Está colado à ideia de representação do outro e dessa representação como forma de conhecimento do outro. Assim como no gênero pictórico, a capa que possui um artista retratado lida com o desafio de dar conta de uma identidade, ou seja, de uma representação e também de uma funcionalidade comercial que, no caso do disco, é a sua divulgação. Não à toa, grande parte das gravadoras prioriza capas estampadas com fotografias de seus artistas. Ao dimensionar a importância das capas como retratos fotográficos, leva-se em conta uma história cultural e midiática do século XX. Associar as capas de Caetano Veloso ao gênero pictórico do retrato é pensar suas múltiplas facetas como super astro. Ainda segundo Shearer West, retratos "são carregados de uma aura de poder, beleza, juventude e outras qualidade abstratas" (2004, p. 43) ${ }^{9}$, assim como as capas de disco onde figuram um cantor ou músico. A imagem de superastro transmitida por Caetano Veloso e o modo como se coloca em cena (postura, acessórios, olhar), são elementos de construção de uma imagem. São também uma forma de autobiografia, na medida em que há, muitas vezes, parentesco com o conteúdo do disco e com a vida do próprio artista e como este se apresenta - ou se representa. Ao retratar, é preciso negociar entre os problemas de representação de identidade: os problemas de deslocação do real para o ideal, ou ainda pensar o retrato como cópia virtuosa ou enganosa, como uma versão de tantos eus possíveis. A respeito desses múltiplos Caetanos, Silviano Santiago aponta que

o superastro vive em toda sua plenitude e contradição comunitária os 365 dias do carnaval e da máscara alheia. Esse é o sonho de Caetano, para ele e para os outros: "em que medida essa explosão [o carnaval] pode se generalizar, pode se estender para o ano inteiro" (SANTIAGO, 2000, p.148)

No retrato, a potência do sujeito revela, desvela e coloca em jogo a estrutura de Caetano. "É deus, é artista, é pessoa: é superior, é diferente, é semelhante. Tudo ao mesmo tempo" (SANTIAGO, 2000, p.150).

\footnotetext{
${ }^{7} \mathrm{Na}$ Grécia antiga, estaria a fixar a imagem do outro pelo traço.

${ }^{8}$ Tradução nossa. No original: "Perhaps more than any other art form, portraiture comes in a variety of media. Portraits can be paintings, sculptures, drawings, engravings, photographs, coins, medals. They can appear as images in newspapers or magazines or on mosaics, pottery, tapestry, or bank notes."

${ }^{9}$ Tradução nossa. No original: "[...] [be] seen to act as a substitute for the individual they represent, or as conveying an aura of power, beauty, youth, or other abstract qualities." 
De todo jeito, ver impressa a figura do cantor, seu rosto, permite ao público associar de imediato a música a um rosto reconhecível. O cantor é imagem. No ensaio sobre a rostidade publicado em Mil platôs (Ano zero: rostidade), Deleuze e Guattari lançam mão de metáforas para dar conta do que é um rosto. Para os filósofos, o rosto é um elemento que envolve política. "O rosto é um verdadeiro porta-voz" (DELEUZE; GUATTARI, 1999, p. 45). Indo além, os signos externos apresentados sobre esses rostos, seus atributos, são também portadores de significados. Em Cores, nomes [Imagem 1], o corpo de Caetano dá poucos indícios: vemos apenas o torso nu, o colar e a guia azul clara. Trata-se da cor do orixá Oxossi no candomblé baiano. No sincretismo baiano, Oxossi é São Jorge. Essa analogia nos remete imediatamente à canção "Cavaleiro de Jorge", na qual ele cita também o "chapéu azul". A presença da guia (que também notamos na capa do disco Outras palavras) aponta para um pertencimento ao candomblé baiano (sabe-se que Caetano frequentou por um tempo o terreiro do Gantois ${ }^{10}$ ), mas lembra também um momento em que a cultura dos blocos afro estava emergindo e ganhando muita força na cena baiana. Não por acaso, uma música do disco homenageia o Bloco Ilê Aiê ("Ilê Aiê, que maneira mais feliz de viver").

Podemos notar ainda que quatro estrelas azuis coroam o chapéu de Caetano. Um recurso muito luxuoso, pois se trata de uma impressão metálica: uma vez pronto, o material voltava para a máquina de impressão apenas para receber essa pequena aplicação. Esse detalhe não é uma mera trivialidade ou enfeite, são quatro estrelas que remetem novamente à canção "Cavaleiro de Jorge": "Cruzeiro do Sul no peito". Ao incorporar tantas referências dessa canção na capa, poderíamos pensar que Caetano encarna ali a figura do cavaleiro de Jorge. Silviano Santiago diz que Caetano Veloso enquanto intérprete "torna-se, ao mesmo tempo, lugar de ver a produção dos contemporâneos e lugar onde ela pode ser vista e analisada". (SANTIAGO, 2008, p.145). No caso deste disco, isso aparece em som e imagem. No envelope interior [Imagem 3], há um folheto que reproduz a capa do disco Seduzir (1981), de Djavan, remetendo a seu dueto com Caetano em "Sina". É uma forma de homenagear Djavan", que, por sua vez, homenageia Caetano, fazendo dele verbo (remeto aqui à canção "Sina" e ao verso "caetanear o que há de bom"). Além de interpretar Djavan, Caetano interpreta ainda Caymmi e Peninha, subvertendo hierarquias culturais através da maneira como constitui seu repertório.

Segundo Disco de Ouro da carreira do Caetano Veloso, Cores, nomes sucede Outras palavras, seu primeiro Disco de Ouro. É evidente que, comercialmente, Caetano estava no auge de sua carreira até então. Conclui-se que é por isso que lhe foi concedido pela gravadora o privilégio de ter uma capa tão sofisticada.

Certa vez, Caetano declarou que Cores, nomes foi lançado em sua fase mais solar, que se dá no início dos anos 1980. Em sua autobiografia Verdade tropical, afirma que os trabalhos feitos em conjunto com A outra banda da Terra (1978-1983) fizeram

\footnotetext{
10 “Aproximei-me do candomblé a partir de conversas bonitas com a ialorixá Mãe Menininha do Gantois" (VELOSO, 2008, p. 485).

${ }^{11}$ É curioso notar também que Djavan não deixa de se referir a si mesmo, uma vez que seu segundo nome é Caetano também. 
parte da "fase de maior felicidade musical [de sua carreira]" (VELOSO, 2008, p. 484). É possível, portanto, associar esse momento às considerações tecidas por Silviano Santiago sobre o período da abertura política no país: "A cultura brasileira [...] se veste das roupas transparentes e festivas da democratização" (SANTIAGO, 2008, p.135). A própria canção "Ele me deu um beijo na boca" testemunha esta abertura política ("E ele me olhou/ De cima e disse assim pra mim/ Delfim, Margaret Thatcher, Menahem Begin/ Política é o fim"). O álbum se apresenta, portanto, como um disco cujas letras já não parecem precisar se preocupar com a censura vigente alguns anos antes. Nesse sentido, a capa é manifestação da escrita visual de uma época, mais precisamente como escrita cultural de determinada época no Brasil.

Uma segunda camada de abordagem, do aspecto formal da capa, aponta para as suas particularidades em termos visuais. Concebida pelos artistas gráficos Luciano Figueiredo e Oscar Ramos, foi elaborada usando também fotos de Maria Sampaio e Lita Cerqueira. Sobre as capas de modo geral, Figueiredo (2015, informação verbal) declarou, em entrevista à autora, que "são um objeto industrial pensado para acompanhar um produto de arte, que é a música". No entanto, esta é feita, de fato, para chamar atenção em meio a tantas outras. Não só em 1982 como em qualquer época, era considerado muito luxuoso ter uma capa impressa por dentro e por fora. E não se trata de um simples capricho, mas da viabilidade de fazer que esta capa se realize enquanto objeto artístico também em sua manipulação. Nisso, ela lembra os trabalhos de interação do participador com a obra, visto nos neoconcretos. Poderíamos dizer que é uma capa que põe em prática o "exercício experimental da liberdade", proferido pelo crítico Mário Pedrosa (1986, p. 308). A capa aqui é, ao mesmo tempo, suporte e objeto artístico, e que se pode ter em casa.

Cores, nomes trabalha constantemente um jogo do dentro e do fora com estratégias de encaixe e sobreposição ${ }^{12}$. A capa é composta de dois invólucros: um exterior e outro interior que se sobrepõe. O invólucro exterior possui recortes na superfície frente e verso da capa. Estes recortes estão materializados numa parte do título do disco (onde se lê a palavra "cores") e no verso (onde há o retrato de Caetano e de seu pai). Ao deslizar a parte exterior sobre a interior, criam-se jogos poéticos graças a um constante vaivém entre o dentro e o fora, que explora estratégias de encaixe e sobreposição, enriquecendo a embalagem do disco.

Ao apresentar poemas visuais inspirados em Mallarmé, Apollinaire, nas vanguardas russas e nos irmãos Campos (todos grandes influências sobre o grupo que concebeu a icônica revista Navilouca - da qual fazem parte Ramos e Figueiredo), valoriza-se o poder da palavra escrita, assim como a visualidade da palavra, sempre pensando em elos com as canções contidas no disco. Nesta capa, letras, palavras e imagens deslizam, se imbricam, se sobrepõem, se encaixam. Há presença de jogos tipográficos, jogos de espelho. Onde se lê "cores", uma tipografia branca; onde se lê "nomes", uma tipografia colorida. Um jogo duplo do encarte com o envelope interior

\footnotetext{
12 Ao manipular a capa do disco, vemos como formas vazadas se sobrepõe ao contorno de letras e poemas visuais. Além disso, é no movimento que se cria o gesto poético que promove um abraço de pai e filho na fotografia da contracapa.
} 
revela formas de letras vazadas, recortadas da capa e onde se leem trechos de "Trem das cores" em forma de poemas visuais. Não é por acaso que os artistas se apropriam tanto da canção mais visual do disco, uma viagem de trem retratada apenas pela memória das cores.

O uso do poema visual em capas de disco é uma constante nas capas feitas por Figueiredo e Ramos, e notamos que ela começa no disco Barra 69 (1971), de Gil e Caetano. Mas aparece ainda em outros, como Fa-tal, de 1972, de Gal Costa onde poemas visuais de Waly Salomão foram aplicados ou Talismã, de Maria Bethânia, por exemplo. Esse conjunto de poemas que podem se movimentar compõe a capa como um poema-objeto. Nenhuma dessas estratégias é gratuita.

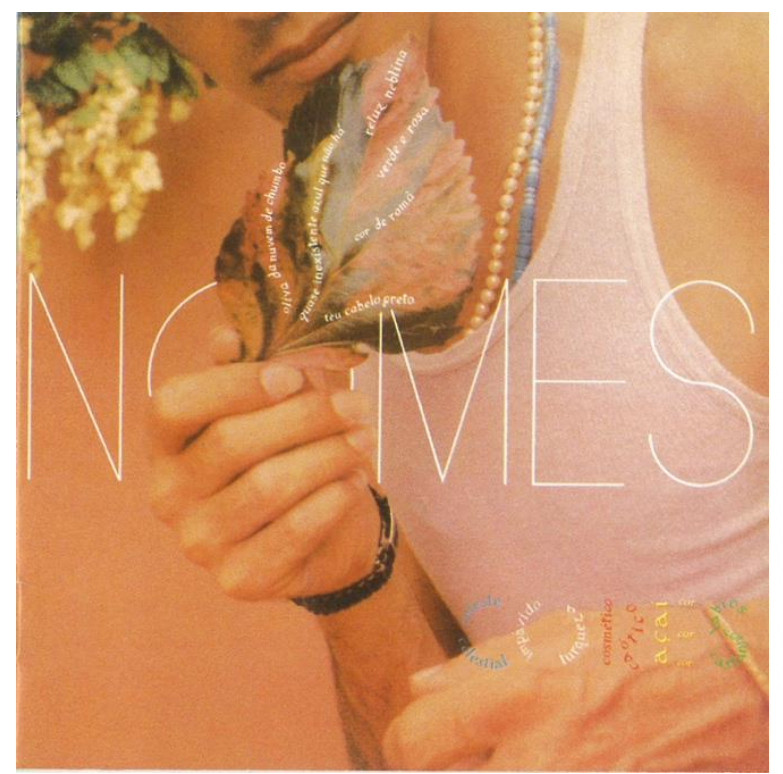

Imagem 3: envelope interior (frente) do disco Cores, nomes.

O trunfo desta capa é justamente ecoar o conteúdo do disco: há uma correspondência entre canções e representações gráficas, que explora ao máximo as possibilidades do suporte capa e da palavra.

Além de todos os jogos poéticos descritos, esta capa abarca ainda uma estratégia muito original, pois a manipulação do envelope interior viabiliza o abraço, o beijo, o encontro entre pai e filho [Imagens 4 e 5], uma referência a "Ele me deu um beijo na boca" e uma homenagem a seu pai, que viria a falecer em 1983. 


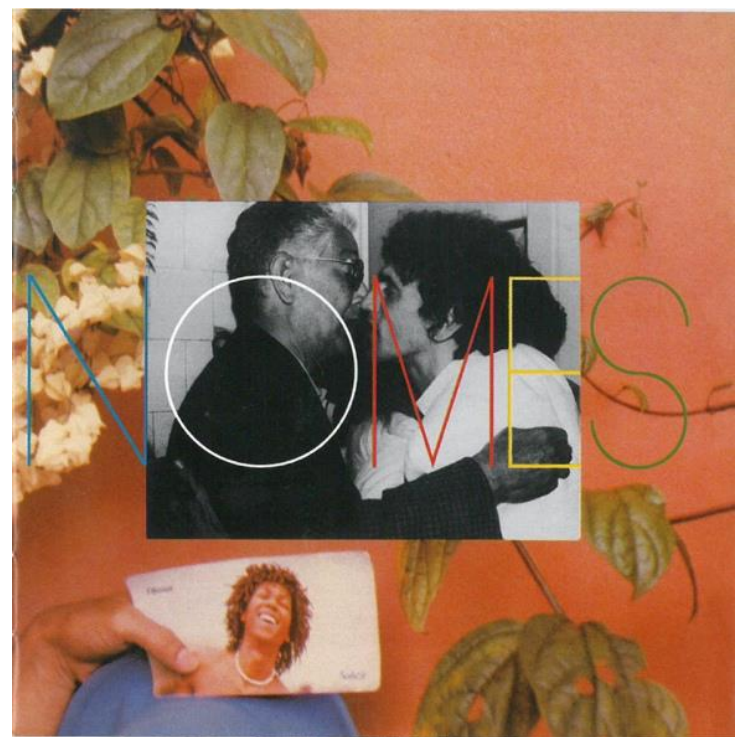

Imagem 4: envelope interior (verso) do disco Cores, nomes.

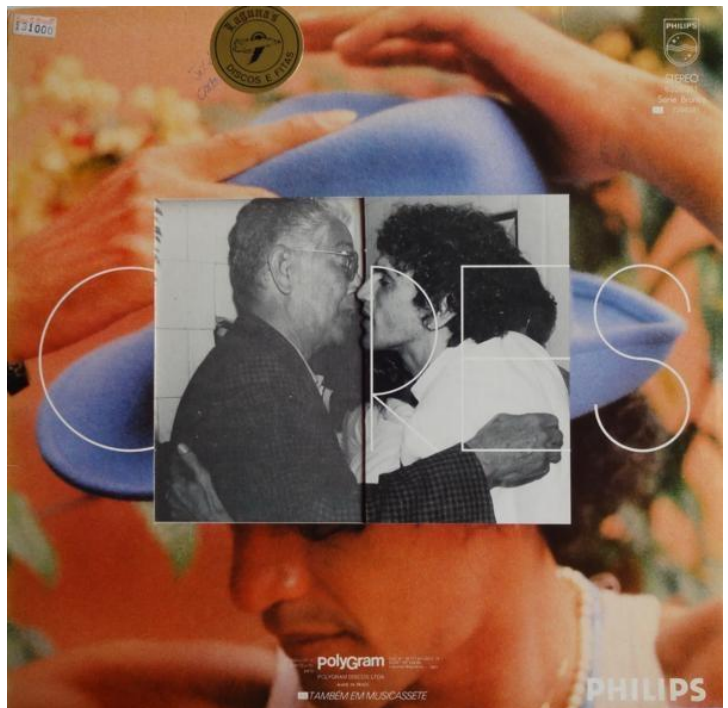

Imagem 5: contracapa do disco Cores, nomes.

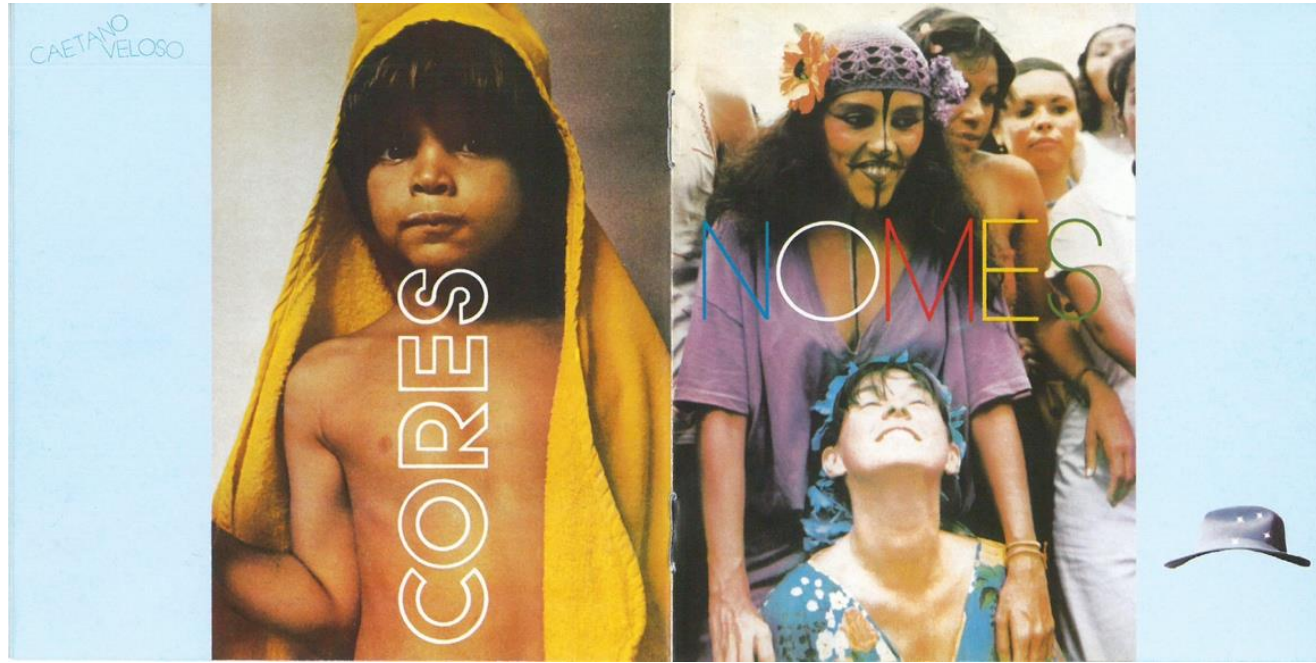

Imagem 6: encarte do disco Cores, nomes.

Revista Escrita

Rua Marquês de São Vicente, 225 Gávea/RJ CEP 22451-900 Brasil

Ano 2017. Número 23. ISSN 1679-6888.

escrita@puc-rio.br 
Por fim, chamo atenção aqui para a filiação (filiatio) e para os laços de amizade (philia) como fios que costuram a complexa trama que é a obra de Caetano Veloso. Sua família e Santo Amaro perpassam não só muitas de suas canções, como suas capas. No encarte do álbum [Imagem 6], veem-se duas fotos: em uma, o filho Moreno, que canta com o pai em "Ilê aiê"; na outra, tirada provavelmente durante o carnaval, a esposa Dedé Gadelha e Regina Casé (a "rapte-me camaleoa" de Outras palavras), grande amiga da família. As fotografias de membros da família e amigos que estampam o encarte (re)afirmam o leitmotiv da família, presente em outras capas do mesmo artista. Neste encarte, temos as três gerações presentes: pai, filho, neto.

Em suas canções, sua relação com a família sempre se fez presente (WISNIK, 2005, p. 104). Em Verdade tropical, Caetano Veloso discorre sobre a importância de seus irmãos: "acho que poderia escrever um livro grande e interessante sobre cada um deles" (VELOSO, 2008, p. 51). A irmã Irene já estava presente no álbum branco (Caetano Veloso, 1969) com a canção homônima. A irmã Nicinha também ganhou uma canção homônima em Qualquer coisa (1975): "Se algum dia eu quiser cantar bonito, muito terá sido por causa de você, Nicinha", diz Caetano na letra da música, mostrando a influência da irmã adotiva sobre sua carreira. Em Bicho (1977), a mesma irmã, Nicinha, empresta sua voz à canção "Alguém cantando". Em Araçá azul (1973), o samba do recôncavo de Santo Amaro penetra o disco via Dona Edith do Prato, que vem a ser a mãe de leite de Caetano e irmã de sangue de Nicinha. Essa influência perdura, por exemplo, no disco Livro (1997), no qual uma canção de seu filho Moreno relembra o toque do prato de Edith e o samba do recôncavo.

Se toda essa genealogia transparece em suas canções e nesta capa, não podemos deixar de pensar no laço familiar que mais parece marcar a obra de Veloso: sua relação musical com a irmã mais conhecida, Maria Bethânia, que se dá até mesmo antes dela gravar sua primeira música (VELOSO, 1977, p. 111). Desde então, a parceria e a troca não tiveram fim. Ainda no mesmo Verdade tropical, Veloso é categórico ao afirmar a importância da irmã Bethânia: "porque ela, além de, como eu, trabalhar com música popular [...], foi determinante na formação do meu perfil profissional e mesmo do meu estilo de compor canções, cantá-las e pensar as questões relacionadas com isso" (VELOSO, 2008, p. 51).

É curioso notar como essa forte presença dos afetos familiares marca não só as canções como as capas de Veloso. Em uma série delas, vê-se a família representada. Poderíamos ver esta representação como um sintoma da fase que marca trabalhos pósvolta do exílio. Na medida em que sentimos que essa afeição pela família permeia as fotografias que embalam seus discos, percebemos que elas dialogam com o conteúdo deles também. Veloso sempre remete às suas raízes, a Santo Amaro. O que vemos aqui são os laços afetivos de uma filiação. 

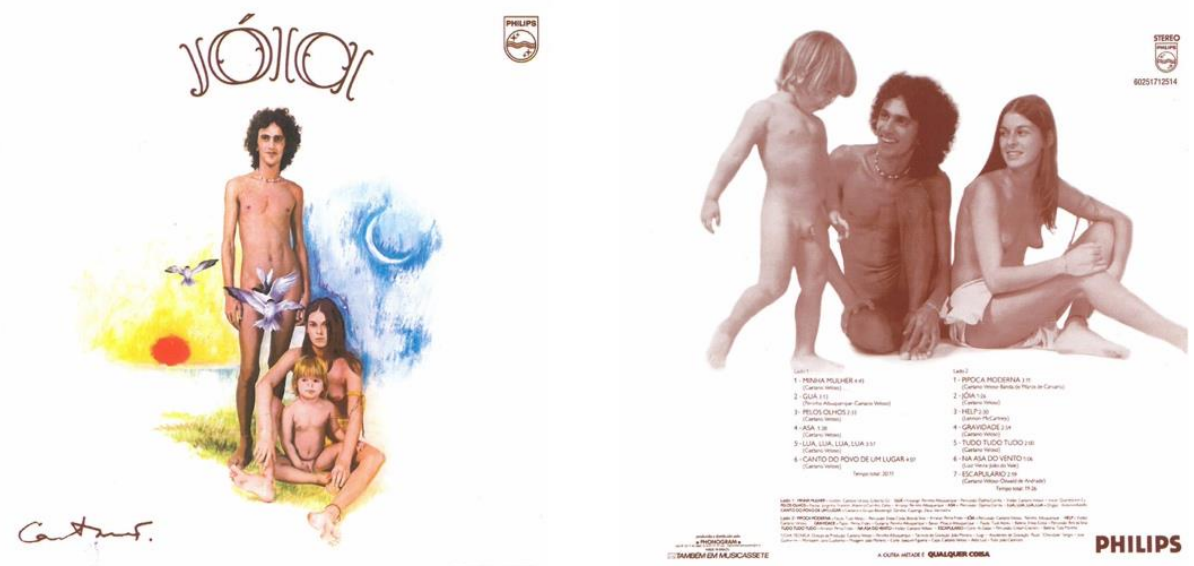

Imagem 7: capa e contracapa do disco Joia, em sua versão não censurada.

Em Joia, de 1975 [Imagem 7], estão retratados ${ }^{13}$ a mulher Dedé e o filho Moreno, desenhados na capa. Nus, como numa família idílica. Na capa de Muito, de 1978 [Imagem 8], Caetano está deitado no colo da matriarca, Dona Canô. A força da mãe em sua obra sempre foi comentada pelo próprio. À época do lançamento do disco, Caetano reagiu quando criticado por aparecer com sua mãe na foto da capa: "[as pessoas] têm vergonha desse negócio de gostar de mãe" (FRANCHETTI; PECORA, 1981, p. 9). No momento do show do disco Muito, Caetano escreve um bilhete por cima do folheto do show (onde consta em página cheia a sua foto no colo da mãe) para a mãe de Milton Nascimento com os seguintes dizeres: "Dona Lília, um beijo carinhoso, de filho, assim: como nesta foto. A senhora se tornou mãe de Bituca, se tornou mãe de muita gente" [Imagens 9]. Não por acaso, Santo Amaro, Dona Canô e as origens de Caetano ganham tamanha amplitude em sua obra.

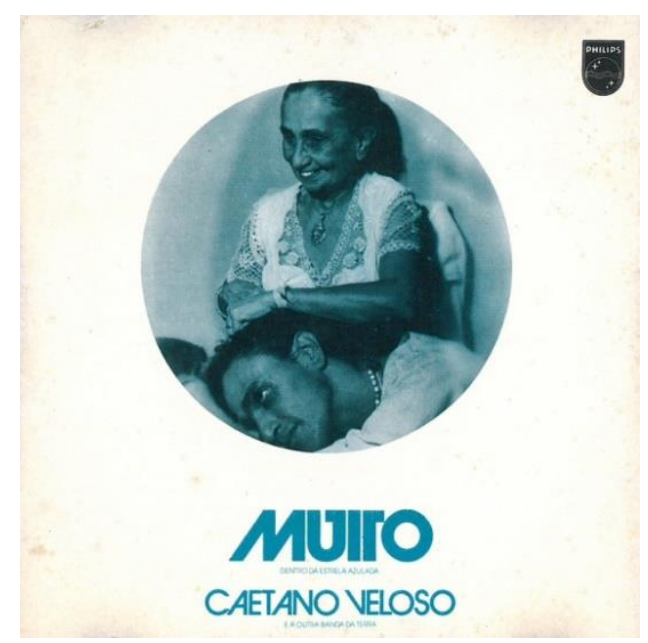

Imagem 8: capa do disco Muito.

\footnotetext{
${ }^{13} \mathrm{Na}$ versão censurada desta capa, este desenho e esta foto foram excluídos. Revista Escrita 


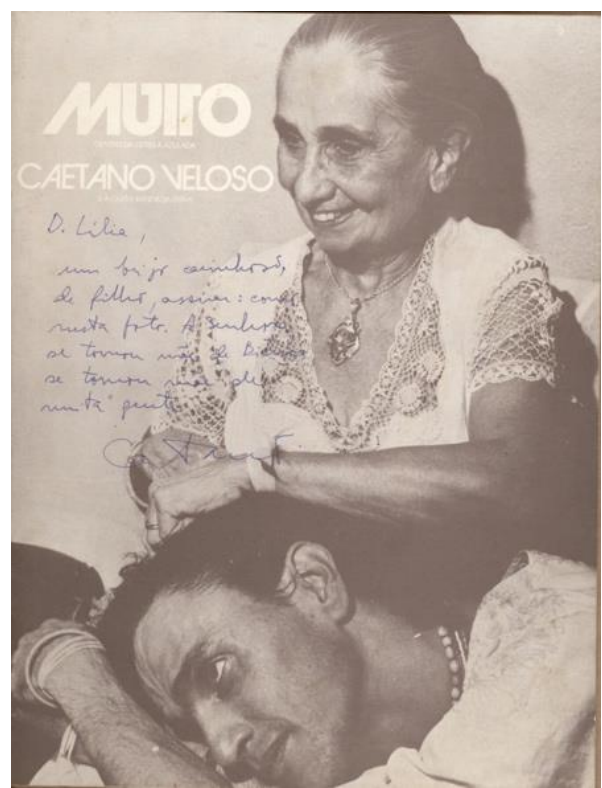

Imagem 9: bilhete de Caetano Veloso para a mãe de Milton Nascimento.

Em Uns, de 1983, ele aparece ao lado dos irmãos Rodrigo e Roberto, e, na contracapa, com sua mãe, seu pai, recém-falecido na época, e Dedé, todos entrelaçados [Imagem 10]. Uns: plurais e únicos na origem. É de grande originalidade notar também que, nesta capa, feita por Oscar Ramos, a palavra Uns é formada por um único módulo curvo que forma todas as letras.

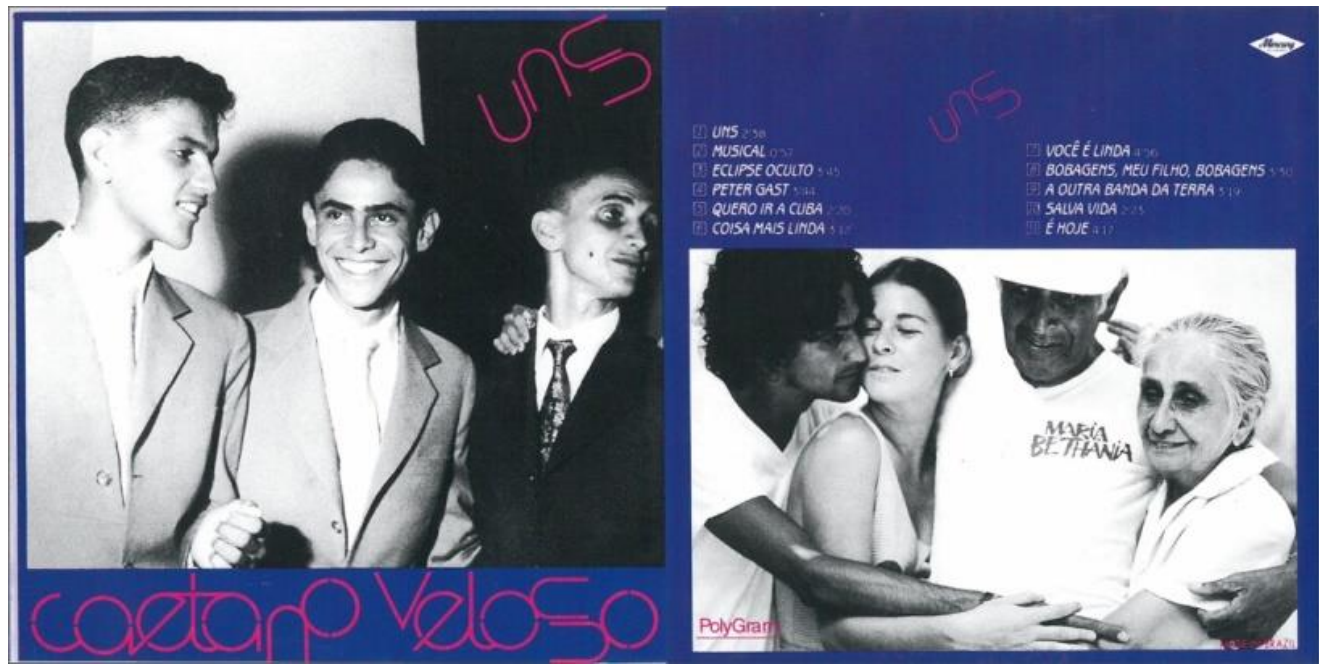

Imagem 10: capa e contracapa do disco Uns.

Mais que testemunharem a importância da filiação na poética musical de Caetano Veloso, estas fotografias o ancoram num real, atestam a veracidade entre o Caetano cantor, pessoa pública e o homem de família, baiano. São dados que, assim como em sua autobiografia, Verdade tropical, dão conta de memórias de infância no interior, costuradas, manipuladas e que contribuem para construir Uns vários "caetanos": ao mesmo tempo recôncavos e reconvexos. Voltando às palavras de Silviano Santiago em "Caetano como superastro", entendemos que: "expondo-se, 
expondo seu cabelo e suas fantasias, seu corpo e sua voz, tornando-se ao mesmo tempo criador e objeto, criador e criado, criado-obrigado de uma plateia cada vez mais exigente" (SANTIAGO, 2000, p. 162), Caetano se aproxima das artes plásticas, pois ele procura a mesma integração de arte e vida proferida pelos movimentos artísticos dos anos 60. Não por acaso, Caetano recorre a artistas plásticos para realizarem as capas de seus discos. Sua música enquanto arte, mas também enquanto vida, constitui a essência de sua obra. As fotografias da família que perpassam tantas capas e principalmente a capa tema deste ensaio, como já foi dito, ancoram Caetano num real e reforçam esse apagamento de fronteiras entre vida e obra. Aqui, tudo é fio que fortalece a trama poética de Caetano.

\section{Referências}

\section{Livros}

DE HOLlANDA, Heloisa Buarque; PEREIRA, Carlos Alberto M. Patrulhas ideológicas. São Paulo: Brasiliense, 1980.

DELEUZE, Gilles; GUATTARI, Felix. Mil Platôs: capitalismo e esquizofrenia. São Paulo: Editora 34, v. 3, $1999 . \quad$ Disponível em: $<$ https://docs.google.com/document/d/1ZxnMU42GNomGv0OTxqcqpPFh5AqA8f9IyH SOOwqGVo8/edit>. Acesso em: 25 nov. 2015.

FRANCHETTI, Paulo; PECORA, Paulo (Org.). Caetano Veloso. São Paulo: Editora Abril, 1981.

PEDROSA, Mario; AMARAL, Aracy (Org.). Mundo, homem, arte em crise. São Paulo: Perspectiva, 1986.

SANTIAGO, Silviano. Caetano Veloso como superastro. In: Uma literatura nos trópicos. Rio de Janeiro: Rocco, 2000, p. 146-163.

Democratização no Brasil - (1979-1981) Cultura versus arte. In: Cosmopolitismo do pobre: crítica literária e crítica cultural. Belo Horizonte: UFMG, 2008, p.134-155.

SCHOLLHAMMER, Karl Erik. Além do visível, o olhar da literatura. Rio de Janeiro: 7 Letras, 2007.

SONTAG, Susan. Sobre fotografia. São Paulo: Companhia das Letras, 2015.

VELOSO, Caetano. Alegria, alegria. Rio de Janeiro: Pedra que Ronca, 1977.

Verdade tropical. São Paulo: Companhia das Letras, 2008.

WEST, Shearer. Portraiture. Oxford: Oxford University Press, 2004.

WISNIK, Guilherme. Caetano Veloso. São Paulo: Publi Folha, 2005.

\section{Discos}


VELOSO, Caetano. Caetano Veloso. Arte da capa: Lincoln. Rio de Janeiro: Philips, 1969. 1 disco sonoro.

Araçá Azul. Arte da capa: Luciano Figueiredo e Oscar Ramos. Rio de Janeiro: Philips, 1973. 1 disco sonoro.

Joia. Arte da capa: Caetano Veloso e Aldo Luiz. Rio de Janeiro: Philips, 1975. 1 disco sonoro. 1977. 1 disco sonoro.

Bicho. Arte da capa: Caetano Veloso e Jorge Vianna. Rio de Janeiro: Philips,

Muito. Arte da capa: Aldo Luiz e Arthur Fróes. Rio de Janeiro: Philips, 1978.

1 disco sonoro.

Outras palavras. Arte da capa: Caetano Veloso, Aldo Luiz e Mariano Martins. Rio de Janeiro: Philips, 1981. 1 disco sonoro.

Cores, nomes. Arte da capa: Luciano Figueiredo e Oscar Ramos. Rio de Janeiro: Philips, 1982.1 disco sonoro.

Uns. Arte da capa: Oscar Ramos. Rio de Janeiro: Philips, 1983. 1 disco sonoro.

Livro. Arte da capa: Luiz Zerbini, Fernanda Villa-Lobos e Barrão. Rio de Janeiro: Polygram, 1997. 1 CD.

\section{Entrevistas}

FIGUEIREDO, Luciano. Luciano Figueiredo: depoimento [20 set. 2015]. Rio de Janeiro. Entrevista concedida à autora.

MACALÉ, Jards. Jards Macalé: depoimento [17 set. 2014]. Rio de Janeiro: Canal Brasil. Entrevista concedida ao programa Arte na capa.

TUNGA. Tunga: depoimento [16 set. 2015]. Rio de Janeiro: Canal Brasil. Entrevista concedida ao programa Arte na capa. 